\title{
Development of a Pediatric Relative Bioavailability/Bioequivalence Database and Identification of Putative Risk Factors Associated With Evaluation of Pediatric Oral Products
}

\author{
Gopal Pawar, ${ }^{1,5}$ Fang Wu, ${ }^{2,5}$ Liang Zhao, ${ }^{2}$ Lanyan Fang, ${ }^{2}$ Gilbert J. Burckart, ${ }^{3}$ Kairui Feng, ${ }^{2}$ Youssef M. Mousa, ${ }^{2}$ \\ Franci Naumann, ${ }^{1}$ and Hannah K. Batchelor ${ }^{4,5}$
}

Received 6 January 2021; accepted 6 April 2021; published online 21 April2021

\begin{abstract}
Generally, bioequivalence (BE) studies of drug products for pediatric patients are conducted in adults due to ethical reasons. Given the lack of direct BE assessment in pediatric populations, the aim of this work is to develop a database of $\mathrm{BE}$ and relative bioavailability (relative BA) studies conducted in pediatric populations and to enable the identification of risk factors associated with certain drug substances or products that may lead to failed BE or different pharmacokinetic (PK) parameters in relative BA studies in pediatrics. A literature search from 1965 to 2020 was conducted in PubMed, Cochrane Library, and Google Scholar to identify BE studies conducted in pediatric populations and relative BA studies conducted in pediatric populations. Overall, 79 studies covering 37 active pharmaceutical ingredients (APIs) were included in the database: 4 bioequivalence studies with data that passed BE evaluations; 2 studies showed bioinequivalence results; 34 relative BA studies showing comparable PK parameters, and 39 relative BA studies showing differences in PK parameters between test and reference products. Based on the above studies, common putative risk factors associated with differences in relative bioavailability (DRBA) in pediatric populations include age-related absorption effects, high inter-individual variability, and poor study design. A database containing 79 clinical studies on BE or relative BA in pediatrics has been developed. Putative risk factors associated with DRBA in pediatric populations are summarized.
\end{abstract}

KEY WORDS: bioequivalence; oral product; pediatric; relative bioavailability; risk factors.

\section{INTRODUCTION}

To ensure therapeutic equivalency, the rate and extent of drug absorption should not be significantly different between generic products and their corresponding reference products when administered at the same molar dose of the therapeutic ingredient under similar experimental conditions in either a single dose or multiple doses $(1,2)$. BE studies form an integral part in generic and new drug products approval process. For assessing BE, PK endpoints such as peak plasma concentration (Cmax) and area under the plasma concentration time curve (AUC), which reflect the rate and extent of drug absorption, are used. According to the U.S. Food and Drug Administration (U.S. FDA), the test and reference products are considered $\mathrm{BE}$ when the $90 \%$ confidence interval of the geometric mean ratios of $\mathrm{Cmax}, \mathrm{AUC}_{0-\mathrm{t}}$, and $\mathrm{AUC}_{0-\infty}$ between the test and reference formulations are within the BE acceptance region of $80-125 \%$ (3). Because the purpose of a BE study is to draw a generalizable conclusion about the test and reference products, BE studies are most often conducted in healthy adult populations. BE studies are designed to compare the test and reference products with the same dosage form in the most sensitive, accurate, and reproducible way. From this evidence, regulators then conclude that the test and reference products can be substituted for all patient populations described in the product label.

Due to the need for age-appropriate medicines with flexible dosing options, pediatric formulations can differ from the product used in adults (e.g., use of a suspension rather than a tablet); thus, a change in relative BA may be possible. Indeed, the pediatric formulation is designed to achieve the target systemic exposure in the population of interest thus a change in PK exposure may be attributable to formulation design. The purpose of relative BA studies, as distinct from $\mathrm{BE}$ studies, is to compare the rate and extent of drug absorption between two pharmaceutical dosage forms (e.g., a novel pediatric formulation) and a reference product (e.g., adult formulation); they are usually conducted in healthy adults (4). Moreover, there is no formal statistical assessment associated with relative BA studies to demonstrate whether they "pass" or "fail" yet sometimes BE acceptance limits are applied to these studies (5). Because relative BA studies are often designed to be descriptive and intended to inform instructions for product use, it is more common to find a 
relative BA study conducted in a pediatric population than to find a BE study conducted in a pediatric population.

Drug absorption differs in pediatric populations compared to adults due to differences in gastrointestinal (GI) physiology and anatomy $(6,7)$. This has led to concerns about comparing pediatric drug product formulations in healthy adults to inform treatment in pediatric populations. Healthy adults are often used as a surrogate population to test the BE of generic and reference pediatric products and to test relative $\mathrm{BA}$ for novel pediatric formulations via a two-way crossover design. Thus, the results from adult population studies (i.e., BE and relative BA studies) are presumed to be the same as in the pediatric population. However, there is a need to identify drug substance or drug products under certain circumstances at risk of discrepancy with the above assumption, so further control strategy/justification can be applied to these products.

When a relative BA study is conducted in adults, the magnitude of difference between the two formulations is often directly applied to the pediatric population to decide the appropriate dose to administer. This was the case with the lamivudine ARROW trial (8), which compared split scoredtablets and solutions of lamivudine in children and showed that the exposure was approximately 55\% higher with the tablet compared to the liquid in children yet the two formulations were equivalent in an adult population (9). The causative agent in this case was presumed to be the sorbitol content of the oral liquid, which influences the GI transit time (10). Thus, an understanding of pediatric anatomy and physiology is required to better predict the impact of drug product dissolution and drug substance solubility on drug absorption. For instance, several reports showed changes in the Biopharmaceutics Classification System (BCS) class for the same drug substance in pediatric compared to adult populations (11-15). A number of risk factors linked to bioinequivalence have been identified from the literature, some examples include: physiological factors (absorption-distribution-metabolism-excretion, ADME effects) (16), formulation effects (10), disease progression and other disease-related effects (17), and poor study design (18).

Despite the notion that $\mathrm{BE}$ established in adults is generally extrapolatable to pediatric populations, there is still a need to identify putative risk factors associated with this concept. This study intended to collect available data from literature that reported bioinequivalence or disparities in PK profiles in BE and relative BA studies conducted in pediatric populations to improve the understanding and identification of any common risk factors that relate to the difference in PK observed.

\section{METHODS}

We systematically searched the literature in PubMed (19), Cochrane Library (20), and Google Scholar (21) for potentially relevant studies that assessed relative $\mathrm{BA}$ and $\mathrm{BE}$ studies in a pediatric population. To collate the largest possible datasets, different search keywords were identified from the literature such as: "bioequivalence" (22); "relative bioavailability" (16); "failed bioequivalence" (23); "lack of bioequivalence" (24); "bioinequivalence" (25), and "nonbioequivalent" (26). In this paper, we used the term "bioinequivalence" to describe cases where the BE criteria were not met and to encompass lack of BE, failed BE, or non-bioequivalent. The combination of search keywords listed in Table I were used to capture data from pediatric populations (aged from 0 to 17 years).

Any duplicate studies identified in more than one database were excluded from the list with the help of EndNote and manual review.

The inclusion and exclusion criteria used to identify relevant high-quality studies are listed in Table II. Two independent reviewers applied these criteria to the identified literature to minimize bias.

A standardized data collection tool was constructed using Microsoft Excel to capture the extracted information under different categories as provided in Table III.

In this paper, we use the term, difference in relative bioavailability (DRBA), to refer to either failed BE studies or studies that demonstrated a difference in relative bioavailability. In this paper, we extracted the reasons that the original authors provided for the change in exposure noted within the studies. This means that the ADME-related differences were those reported in the original studies and it may well be an interplay between the formulation and the absorption This could also include links to secondary references where authors interpreted their data in the context of wider literature.

The physicochemical drug properties, including molecular weight, $\log \mathrm{P}$, and water solubility, as well as oral BA (\%), were extracted from the Drug Bank database (27). Narrow therapeutic index (NTI) data for the drugs where "small differences in dose or blood concentration may lead to dose and blood concentration dependent, serious therapeutic failures or adverse drug reactions that are life-threatening or result in persistent or significant disability or incapacity" (28) were identified using information within product-specific guidances (PSG) where the U.S. FDA identified drugs as NTI (29). The BCS classification for those drugs included was reported from the NICHD-FDA report (30) and from specific publications relating to the development of provisional pediatric BCS systems $(6,14,15,31)$. Both adult and pediatric BCS classifications are reported to enable comparison within these populations and to identify those drugs where the BCS classification changes between adult and pediatric populations.

\section{RESULTS}

A total of 79 clinical studies containing data from pediatric populations were identified using the search terms listed above and applying the inclusion and exclusion criteria (Supplementary Material 1, database for relative BA and BE studies in pediatrics). Subsequently, a total of 41 studies with DRBA results between test and reference products remained for further analysis (Supplementary Material 2, risk factor summary). The 41 studies included $2 \mathrm{BE}$ studies and 39 relative BA studies that showed disparities in PK properties when test and reference produces were compared.

These 41 (2 BE and 39 relative BA) studies were interrogated to identify the reported putative risk factors that could be responsible for the failure of BE in pediatrics. A summary of these risk factors is shown in Table IV. 
Table I. Combination of Search Keywords Used To Identify Relevant Literature. Note for Google Scholar, We Omitted "OR” and “AND” With the Keywords

\begin{tabular}{ll}
\hline To identify relevant studies & "Bioequivalence" OR \\
& "Relative Bioavailability" OR \\
& "Non-Bioequivalent" OR \\
& "Failed Bioequivalence" OR \\
& "Lack of Bioequivalence" OR \\
& "Bioinequivalence" \\
& AND \\
& "Infant" OR "Child" OR "Children" OR "Adolescent" OR "Pediatric" \\
To limit to a pediatric population & AND \\
& "Oral drug" \\
To limit to orally administered products & \\
\hline
\end{tabular}

Further details and examples of studies are described in the text below.

\section{Physiological Factors (ADME Effect)}

\section{Age-Related Absorption Effects}

As listed in Table IV, 28 studies reported DRBA attributed to age-related absorption (differences in absorption between pediatric and adult populations). Fifteen out of 28 studies reported multiple absorption-related risk factors $(8$, 32-45), including alterations in GI transit time or motility (8, $33,36,38,40,44)$, changes in GI fluid composition $(37,40)$, and different levels of saturation for intestinal transporters/ metabolism $(8,42)$. Moreover, 11 of the studies from the list of 28 reported factors are also related to the formulations used $(32,34-41,43,45)$, and 5 also related to the drug substance $(8,33,38,40,44)$. It should be noted that a $\mathrm{BE}$ study conducted as a crossover study would cancel out the age-related effects on clearance and highlight those effects that are related to formulation differences; however, due to the limited crossover BE studies conducted in pediatric populations, we summarized all the risk factors related to applying clinical study results from adults to pediatric populations. GI Transit. Altered GI transit time in children as compared to adults was listed as a risk factor for DRBA. For example, an emtricitabine capsule formulation provided $20 \%$ higher plasma exposure compared to the solution formulation in children reportedly due to the fact that the GI transit time of the solution was shorter than that of the capsule formulation (44).

The rapid GI transit in children has been implicated as a risk factor for DRBA for drugs such as cyclosporine A (33, $36,38)$. This risk factor is associated with formulation changes that alter the rate of drug release $(33,36,38,46)$. In previous studies conducted in adults, factors including bile flow, GI motility, bowel length, and food intake and composition were found to affect the absorption of certain cyclosporine formulations (38) and phenytoin (40). There is an interplay between formulation effects and GI transit, and if GI transit time limits drug absorption, differences in formulation may have impact on the absorption. Thus, the implications of these effects in adult studies may increase in pediatric populations (40).

In neonates and infants below the age of 6-8 months, gastric emptying was found to be slower due to immaturity of the neuroregulation of gastric motility (69). Evidence on differences in GI transit between adults and children is conflicting and there is very limited detailed information on gastric emptying and small intestinal transit times in pediatric populations $(70,71)$. There is evidence that shorter transit times of solutions compared to solid dosage forms in adults were observed from one study comparing solutions, small pellets, and tablets in adults (72) and from a second study comparing the pharmacokinetics of alendronate solution and tablets (73). Thus, a change in formulation from solid to liquid may be associated with shorter transit time in pediatric populations; this is likely to be exacerbated for monolithic controlled release tablets as their relative size may delay

Table II. Inclusion and Exclusion Criteria Used To Identify the Studies To Be Included in Further Analysis

I n c l u s i o n - Studies conducted on U.S. FDA or European Medicines Agency (EMA) approved drugs for oral administration only.

criteria $\quad$ Studies must include data from pediatric populations.

- The studies must provide information on study design (e.g., randomized controlled, crossover design, and parallel design), subjects information (age, weight, height, sex, origin, inclusion, or exclusion criteria), sample size, dose of the drugs (single or multiple), washout period, study conditions (fasting or fed state), and clinical trials registration ID.

- BE studies must report the statistical analysis containing the $90 \%$ CIs $(80-125 \%)$ or geometric mean ratios $(0.8-1.25)$ for both the test and reference medicines for the PK endpoints AUC and Cmax. Studies should also state whether they met the BE criteria according to U.S. FDA or EMA guidelines.

- For relative BA studies, PK endpoints such as AUC and Cmax data are required for tested and reference products.

E x c l u s i o $\mathrm{n}$ - Studies on drugs not administered orally.

criteria - Studies reporting difference in relative bioavailability (DRBA) due to the presence of food or drinks or herb-drug interactions or drug-drug interactions. 
Table III. Details of Information Extracted From Each Study Identified Within the Literature Search

\begin{tabular}{|c|c|}
\hline Study details & $\begin{array}{l}\text { Study title; URL link; study design (i.e., randomized controlled, parallel, or cross-over); sample size; dose } \\
\text { administered; single or multiple dose }\end{array}$ \\
\hline Study population & Age; healthy/diseased state; number of participants \\
\hline $\begin{array}{l}\text { Test and reference } \\
\text { products }\end{array}$ & $\begin{array}{l}\text { Dosage form and strength of the test and reference products (i.e., tablet and capsule); pre-dosing manipulations (e.g., } \\
\text { halving or quartering or crushing the tablets before administration) }\end{array}$ \\
\hline Administration details & Fasted/fed state; volume of water consumed $(\mathrm{ml})$ \\
\hline Study results & $\begin{array}{l}90 \% \text { CIs }(80-125 \%) \text { or geometric mean ratios }(0.8-1.25) \text { for both the test and reference medicines for the PK } \\
\text { endpoints AUC and Cmax; statistics }\end{array}$ \\
\hline Interpretations & Authors interpretation of data on product equivalence (Yes/No) \\
\hline $\begin{array}{l}\text { Risk factors for } \\
\text { DRBA }\end{array}$ & Original authors' reasons for DRBA stated in the paper \\
\hline $\begin{array}{l}\text { Clinical impact of } \\
\text { DRBA }\end{array}$ & Authors interpretation of data on clinical equivalence (Yes/No) \\
\hline Miscellaneous details & Clinical trials registration ID; remarks; reference \\
\hline
\end{tabular}

passage through the pyloric sphincter, as observed with a quicker onset of action for multi-particulate formulations compared to single unit tablets $(74,75)$. However, it should be noted that there is currently no evidence on the relative gastric emptying or intestinal transit time of liquid and solid oral dosage forms in pediatric populations.

Saturation of GI Transporters. The authors reported that oral administration of highly soluble drugs may lead to very high local concentrations of active components in children resulting in saturation of GI membrane influx or efflux transporters leading to altered BA (8). For liquid dosage forms, the drug is already homogenously dissolved or dispersed within the solvent yet dissolution from solid oral dosage forms can lead to regions of highly concentrated drug in solution. The impact of high local concentrations saturating GI membrane transporters was identified as a risk factor in the higher exposure of lamivudine tablets compared to an oral solution in children (8). Saturation of GI membrane transporters was also identified for a BCS class 3/1 drug sulfadoxine (76) as a risk factor in a study where there was a $32 \%$ reduction in the relative $\mathrm{BA}$ of sulfadoxine (in combination with pyrimethamine) when the dose was doubled in infants with malaria (42). Previously, the concept of saturation of efflux transporters has been highlighted as a theory yet not considered to be clinically relevant $(77,78)$; thus, further research is required to better understand the true likelihood of saturation of transporters in pediatric populations leading to clinically significant changes.

\section{Age-Related Distribution Effects}

Two studies were identified with DRBA attributed to differences in the volume of distribution $(40,47)$ : one specifically identified protein binding (40) and another study identified intracellular drug transport as risk factor for DRBA (47).

The volume of distribution of drugs has been reported to change with age. In younger children, higher doses of hydrophilic drugs are required because of the higher percentage of water content in their body; however, lower doses of hydrophilic drugs are required in older children due to the increased proportion of body fat (79). Neonates have lower plasma protein bindings which may increase the fraction unbound for certain highly protein bound drugs and lead to higher plasma exposure (80).

\section{Age-Related Metabolism or Clearance Effects}

Fifteen studies were identified with DRBA due to changes in metabolism or clearance $(32-34,36,42,43,47-$ 50, 58-62). Differences in enzyme expression and activity can result in altered metabolism of drug substance, which may result in altered production or accumulation of the metabolites. A classic example is gray baby syndrome where the immaturity of hepatic UDP-glucuronyl transferase enzymes in babies leads to accumulation of chloramphenicol metabolites and subsequent toxicity (81).

Variability in genetic polymorphism associated with certain metabolic pathways may increase the likelihood of DRBA (82). This was implicated as a risk factor in a study on lopinavir/ritonavir which are substrates of the multi-drug resistance gene (MDR-1) and organic anion-transportingpolypeptide (OATP) drug transporters as well as some CYP450-based metabolism in the GI tract (47).

Risks for DRBA were also reported (in 1986) for alternative phenytoin (generic tablets and capsules) in epileptic children where dose-related saturation of hepatic metabolizing enzymes or binding proteins could lead to higher plasma concentrations as a result of the small change in dose/exposure resulting in toxicity (49).

Since several other studies conducted in adults have highlighted issues changing phenytoin brand (83) for reasons including a change in excipients (from calcium sulfate to lactose) (84); differences in the physicochemical properties of excipients (85); differences in uniformity of content (86); stability issues (86), and ethnic differences in metabolism (87). Current advice in the UK is to remain on the same brand of phenytoin where possible (88). In addition, as FDA has concluded that phenytoin is an NTI drug (within the product-specific guidance), thus the in vivo BE study should be a fully replicated crossover design in order to scale bioequivalence limits to the variability of the reference product and meet the unscaled average BE criteria and 
Table IV. Summary of Stratification of Author's Reported Reasons for Failed Pediatric BE and Relative BA Studies Identified Within This Review. Note That Multiple Reasons May Have Been Listed for a Single Study

\begin{tabular}{|c|c|c|c|}
\hline & Putative risk factors & $\begin{array}{l}\mathrm{N} \mathrm{u} \mathrm{m} \mathrm{b} \mathrm{e} \mathrm{r} \text { of } \\
\text { studies identified }\end{array}$ & References \\
\hline \multirow[t]{3}{*}{$\begin{array}{l}\text { Physiological factors } \\
\text { (ADME effect) }\end{array}$} & $\begin{array}{l}\text { Age-related absorption effects (e.g., GI motility, GI fluid } \\
\text { volume or composition, and GI transit time) }\end{array}$ & 28 & $(8,26,32-57)$ \\
\hline & Age-related distribution effects (e.g., protein binding) & 2 & $(40,47)$ \\
\hline & Age-related metabolism or clearance effects & 15 & $\begin{array}{l}(32-34,36,42,43,47-50,58- \\
62)\end{array}$ \\
\hline \multirow[t]{2}{*}{$\begin{array}{l}\text { Drug substance or } \\
\text { formulation effects }\end{array}$} & $\begin{array}{l}\text { Drug substance effect (e.g., alternative salt or polymorphic form } \\
\text { of drug substance) }\end{array}$ & 5 & $(34,35,39,40,51)$ \\
\hline & Drug product/formulation effects & 12 & $(32,34-41,43,45,63)$ \\
\hline Disease & $\begin{array}{l}\text { Age-related disease progression and other disease-related } \\
\text { effects }\end{array}$ & 4 & $(26,53,63,64)$ \\
\hline $\begin{array}{l}\text { Population } \\
\text { characteristics }\end{array}$ & High inter- and/or intra-individual variabilities & 18 & $\begin{array}{l}(33,36-39,41,45-48,50,54,55, \\
58,61,63,65,66)\end{array}$ \\
\hline \multirow[t]{3}{*}{ Study design } & Non-equivalent dose effects & 2 & $(39,67)$ \\
\hline & Accuracy of administered dose & 2 & $(60,68)$ \\
\hline & Poor study design including small sample size & 11 & $\begin{array}{l}(35,43,44,49,51-53,59,62,66, \\
67)\end{array}$ \\
\hline
\end{tabular}

compare test and reference product within-subject variability (89).

\section{Drug Substance and Formulations Effects}

\section{Drug Substance Effects}

Five of the identified studies reported drug substance properties (e.g., salt form, intrinsic solubility, and crystal form) as factors associated with DRBA (34, 35, 39, 40, 51). Here, "drug substance" refers to the active ingredient and includes properties related to particle size, salt form, and intrinsic solubility. For drugs such as rifampicin and tacrolimus, poor solubility has been highlighted as one of the confounding reasons for DRBA $(35,51)$.

DRBA between hydrocortisone suspension (Cortef: 10 $\mathrm{mg} / \mathrm{ml}$, suspending agent-xanthan gum) and a tablet was observed in 19 children; as a result, the liquid formulation was recalled from the market (39). The liquid formulation in this study contained hydrocortisone cypionate, an ester form of hydrocortisone which is different from the free hydrocortisone used in previous suspension formulation used in adult study (90). In adult study, the suspension formulation of free hydrocortisone showed higher absorption compared to the tablets and a shorter half-life than hydrocortisone tablets; they are not BE to each other either.

The crystal form plays an important role in the absorption of pharmaceutical active ingredient. The manufacturing process of rifampicin (RMP) could result in the formation of either polymorphic or amorphous state of RMP with eightfold difference in water solubility between the two states (91). Consequently, RMP exposure was found to be $76 \%$ lower among children who received the R-Cin ${ }^{\circledR}$ suspension compared to Eremfat ${ }^{\circledR}$. The study highlighted that the differences in BA between the two suspension formulations were due to the mixture of polymorphic forms of RMP in R-Cin ${ }^{\circledR}$ that was not favorable for absorption (51). The solubility of any material is dependent upon the volume and composition of the solvent; there are known differences in the intestinal fluids between adults and children thus the relative difference in the formulation may not be directly transferable.

The particle size of sodium phenytoin can affect its oral BA; three separate studies have demonstrated that smaller particles dissolve more rapidly and have increased BA compared to larger particles $(34,40,92)$.

The intrinsic poor solubility of certain drugs can increase risks of non-linear PK due to incomplete dissolution within the GI tract $(35,49,52,63)$, especially for children whose GI volume is less compared to adults (93).

\section{Drug Product/Formulations Effects}

Drug product effects may change the exposure to a drug substance due to changes in dosage form (e.g., tablet versus capsule or liquid oral formulation), drug release profiles (e.g., immediate or extended release or complex release formulation), and formulation constituents (e.g., excipient effect). Drug product effects are typically reflected in relative BA studies.

From the relative BA studies identified, 12 studies showed drug product effects on BA $(32,34-41,43,45,63)$. The magnitude of drug product effects may be amplified in pediatric populations where differences in absorption relate to factors such as GI motility where small formulation changes can result in large PK differences as shown with controlled release formulations $(33,38,40,44)$.

Neoral (microemulsion of cyclosporin A) was rapidly absorbed in children producing a high peak level within 1 to $2 \mathrm{~h}$ of dosing. This observation was due to the increased effective surface area achieved by the microemulsion compared to a more conventional formulation $(33,36-38,45)$.

Three studies reported DRBA due to excipient effects (32, 34, 63). For extemporaneously prepared 6mercaptopurine (6-MP) liquid formulations, differences in formulation constituents (excipients) and viscosity, and potentially 6-MP could have contributed to the observed variability in systemic drug availability from liquid formulations (63). Lactose, which is an excipient widely used as a 
filler or filler-binder in the manufacture of tablet and capsules, could aid in moistening of the phenytoin particles in tablet formulation and this enhanced the dissolution rate followed by increase in absorption and plasma exposure (34).

\section{Age-Related Disease Progression and Other Disease-Related Effects}

FDA's Guidance for Industry: Providing Clinical Evidence of Effectiveness for Human Drug and Biological Products recommends that the efficacy data from adult population can be extrapolated to pediatric population when the course of the disease and the effects are sufficiently similar (94). In our analysis, 4 studies attributed the DRBA reported to differences in disease progression between adults and children $(26,53,63,64)$. These diseases include HIV; congenital hypothyroidism; malaria; epilepsy; attention deficit hyperactivity disorder (ADHD), and organ transplant. For example, in HIV-infected children, co-administration of antibiotics with anti-HIV drugs have been reported to (i) decrease the absorptive surface area of the intestine (95), (ii) alter gut flora (96), (iii) cause local GI inflammation (97), (iv) lead to fat malabsorption (98), and (v) cause diarrhea (99). All of these effects were shown to alter the BA of the antiHIV zidovudine in children (100). In another example, Synthroid and one of its generic L-T(4) versions were observed to have a different pharmacodynamic response in children $(n=36)$ suffering from congenital hypothyroidism $(\mathrm{CH})$ due to diminished thyroid reserve (26).

\section{Population Characteristics}

A total of 18 studies linked DRBA to population effects from participants in the study. These population effects include: high inter-individual variability within the study population $(33,36-39,41,45-48,54,55,58,61,63,65,66)$, high intra-individual variability $(45,50,63)$, or genetic polymorphism associated with metabolism of drugs (47, 58, 65). The consequences of these population effects may increase in the developing pediatric population. For example, pediatric liver transplant recipients are known to show poor and variable absorption of cyclosporin partly because of the limited absorptive surface area associated with small bowel lengths $(36,101)$, surgical bowel reconstruction, and also due to higher rates of metabolism of cyclosporine $(36,55)$.

\section{Study Design}

Dosing issues and poor study design were listed as a risk factor for DRBA in 15 studies, as detailed in Table IV.

\section{Non-equivalent Dose and Accuracy of Administered Dose}

Non-equivalent dose may play a role in the DRBA of the tested medicines such as hydrocortisone and levothyroxine $(39,67)$. In addition, extemporaneous preparation of products such as hydrocortisone and nevirapine may make dose accuracy within the test questionable $(60,68)$.

\section{Poor Study Design Including Small Sample Size}

Failure to meet BE criteria may occur as a result of underpowered studies (102). Eleven studies reported DRBA due to an underpowered study design $(35,43,44,49,51-53$, 59, 62, 66, 67).

Small sample size was a factor behind the DRBA reported in 7 of the original 11 studies $(43,44,51,53,59$, $66,67)$. One of the studies already highlighted recruited small sample sizes $(n=2-10)$ due to the nature of study population, for example, patients with organ transplant (59). Risk factors of poor study design from the studies already identified include: non-randomized study design (44, 62, 67, 103); parallel study arms (35); retrospective study design (104); methodology used in statistical results (e.g., partial AUC calculations were not considered for complex release methylphenidate formulations) (104), or baseline errors for endogenous molecules (e.g., levothyroxine (105)).

\section{Further Analysis on BCS Classification of Drugs Showing DRBA Results}

The BCS classification of the drugs included in the studies were reported as those based on adult data and those relevant to the pediatric data as described in "METHODS." Table V summarizes the BCS classification and NTI of each drug where DRBA was reported.

BCS 2 drugs were the most commonly reported with DRBA, perhaps unsurprisingly as poor solubility is associated with greater variability in plasma exposure $(108,109)$. The proportion of BCS 2 drugs $(55.5 \%)$ listed here was lower to the proportion of BCS 2 drugs mentioned in a previous study (based on AUC criteria in healthy, young volunteers) where $63 \%$ of drugs were BCS class 2 DRBA products (110).

\section{Further Analysis on NTI Classification of Drugs Showing DRBA Results}

In this study, the NTI drugs made up $28 \%$ of those where DRBA was reported. The proportion of NTI drugs within this study appears to be lower than the proportion previously reported in a similar study (based on a small subset of products from 2005 to 2008 ) (28\% in this study compared to $56 \%$ in the previous study) (22) (111). However, it should be noted that the previous study used a much smaller sample size ( $n=9$ DRBA studies) where data mining was conducted for 3 years and only 9 DRBA studies were identified out of 79 articles in their analysis. The high proportion of NTI drugs where DRBA was reported in the current study is unsurprising indicating that NTI is a risk factor and the challenges in demonstrating bioequivalence for NTI products have already been highlighted (112).

The data shows that the proportion of those drugs showing DRBA that were NTI drugs is highest in the BCS 2 and then followed by 3 and 1 (highly soluble) classifications. This may be expected, as highly soluble drugs are more likely to show equivalence than BCS class 2 drugs. This is further supported by the U.S. FDA guidelines on waiver of in vivo $\mathrm{BA}$ and $\mathrm{BE}$ studies for immediate release solid oral dosage forms based on BCS class 1 and 3 system and also it is mentioned that the BCS-based biowaivers are not applicable 
Table V. BCS Classification of Drugs According to Adult and Provisional Pediatric BCS System

\begin{tabular}{lllll}
\hline Drugs showing DRBA & Adult BCS class & Pediatric BCS class & Type of study & Representative reference(s) \\
\hline Carbamazepine & 2 & 2 & Relative BA & $(48)$ \\
Cyclosporine & 2 & 2 & Relative BA & $(57)$ \\
Efavirenz & 2 & 2 & Relative BA & $(43)$ \\
Emtricitabine & 1 & $1^{*}$ & Relative BA & $(44)$ \\
Hydrocortisone & 1 & $3 / 4^{\#}$ & Relative BA & $(39)$ \\
Indinavir & $2 / 4$ & $2 / 4^{*}$ & Relative BA & $(41)$ \\
Lamivudine & 3 & 3 & Relative BA & $(8,64)$ \\
Levothyroxine & 1 & 1 & Relative BA & $(67)$ \\
& & & BE & $(26)$ \\
Lopinavir & 2 & 2 & Relative BA & $(66,106)$ \\
6-Mercaptopurine & 4 & $2^{\#}$ & Relative BA & $(63)$ \\
Nevirapine & 2 & 2 & Relative BA & $(58)$ \\
Phenytoin & 2 & 2 & Relative BA & $(34,49)$ \\
Pyrimethamine & 4 & $2^{\#}$ & Relative BA & $(42)$ \\
Ritonavir & 2 & 2 & Relative BA & $(66,106)$ \\
Rifampicin & 2 & 2 & Relative BA & $(51)$ \\
Stavudine & 3 & 3 & Relative BA & $(64)$ \\
Sulfadoxine & $3 / 1$ & $3 / 1^{*}$ & Relative BA & $(42)$ \\
Tacrolimus & 2 & $2^{*}$ & BE & $(52,59)$ \\
Vitamin E & Not classified & Not classified & Relative BA & $(103)$ \\
\hline
\end{tabular}

${ }^{*}$ Drug BCS class in pediatric is assumed to be same as that of adult BCS class where no provisional pediatric BCS class has been assigned for these drugs

\# 4 Drugs exhibit BCS class shift (2 favorable (BCS 4 to 2) and 2 non-favorable shift (BCS 1 to 3 and BCS 3 to 4)). Drugs name in bold are NTI drugs otherwise non-NTI class

for NTI drugs (and products designed to be absorbed in the oral cavity) $(113,114)$.

A comparison of the relative frequency risk factors for the studies is presented in Fig. 1. These are shown based on their pediatric BCS and non-NTI and NTI classification to identify where risks were most prevalent. Fig. 1 demonstrates that BCS class 2 drugs occupy the largest percentage of the DRBA cases where risk factors of age-related absorption effect, drug substance/drug product effect, and high inter- and intra-variabilities are identified.

\section{DISCUSSION}

From Fig. 1, it is evident that age-related absorption risk factors for DRBA were mainly attributed to BCS class 2 nonNTI drugs (rifampicin, indinavir, efavirenz, pyrimethamine, lopinavir, ritonavir) and NTI drugs (e.g., carbamazepine, cyclosporin, phenytoin, and tacrolimus). The low solubility of BCS class 2 drugs at the site of absorption may lead to erratic absorption of NTI drugs. Moreover, only BCS class 2 (e.g., phenytoin) and BCS class 3 (e.g., lamivudine) drugs were identified as having DRBA risks due to age-related distribution effects. BCS class 2 drugs were observed at higher frequency for both non-NTI and NTI drugs for age-related metabolism risk factors. Interestingly, not a single case study or risk factor that related to excretion was found in the pediatric population.

Interestingly, drug substance-related risk factors were observed most often in BCS class 2 (non-NTI $(n=1)$; NTI $(n=2))$ drugs. The differences in $\mathrm{BE}$ results due to drug products are seen at the highest frequency with both BCS class 2 categories for NTI drugs ( $n=3$ for BCS class 2 ). Moreover, both NTI and non-NTI BCS class 2 and 3 drugs showed DRBA due to disease progressions and other disease-related effects. Surprisingly, BCS class 1 NTI drugs (e.g., levothyroxine) despite having good solubility and permeability were also found to result in DRBA in a pediatric population although in this study, the claim of a difference in bioequivalence was based on the pharmacodynamic endpoint (thyroid-stimulating hormones) with smaller observed differences in the levothyroxine exposure. This is further supported by literature studies conducted for levothyroxine products in healthy or diseased adults $(111,115)$, and it is worth noting that the evidence of DRBA is not specific to the pediatric population. The poor stability of levothyroxine sodium tablets has been highlighted as they have been recalled many times since their 1955 introduction to the US market (116).

BCS class 2 ( $n=6$ for non-NTI and $n=2$ for NTI drugs) and BCS class 3 ( $n=2$ for non-NTI) contributed notably for the observed inter- and intra-individual variations resulting in DRBA. The reason for inter- and intra-individual variations could be due to the physiological complexity of the GI tract and the physicochemical properties of the drug substance. The inter- and intra-individual variations in PK parameters are higher in pediatric population as compared to adults (92) due to the influence of growth, maturation, diurnal variations, pharmacogenetic reasons, the pre-systemic metabolism of the drug substance, etc. $(48,61,117)$. The variations in PK parameters could be minimized by increasing the study power to $>80 \%$ and conducting a two-way, crossover single dose study (118). Our results indicated that low sample size and poor study design contributed as risk factors for DRBA results. 


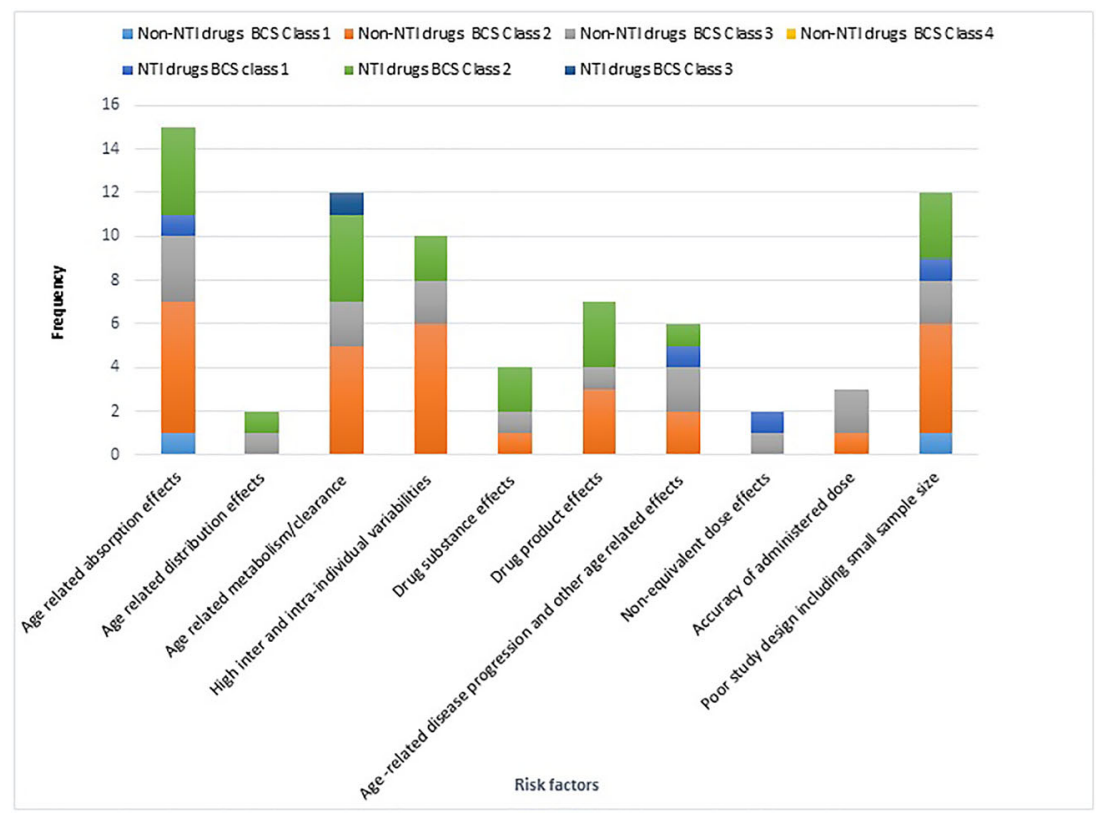

Fig. 1. Bar chart showing the number of clinical trials involving non-NTI or NTI drugs under each risk factors analyzed

The collated risk factors resulting in DRBA will need to be further evaluated but could potentially serve as checkpoints during innovative pediatric formulation development, optimization of the prediction of a pediatric dose, and the extrapolation of $\mathrm{BE}$ results based on the clinical studies in adults. However, it should also be borne in mind that DRBA due to the aforementioned risk factors does not mean therapeutic inequivalence of pediatric medicines (119). If the final or to-be-marketed pediatric formulation is used in the pivotal pediatric clinical study for an innovator product, a BE/relative BA study for this product is not necessary. Any change to the formulation utilized in the pivotal study may trigger a clinical bridging study. It was not possible to generate sufficient data to stratify findings into subsets of the pediatric population (neonates, infants, children, and adolescents), yet this would be useful and additional data is needed to fully understand how risks of DRBA change with age within the pediatric population. Further work is warranted to also compare the magnitude of differences observed for the BE or relative BA data identified from the pediatric population with similar data from the adult population to fully evaluate the limitations of using adult data to predict the $\mathrm{PK}$ in pediatric populations.

\section{CONCLUSION}

A database containing clinical studies on $\mathrm{BE}$ or relative $\mathrm{BA}$ in pediatrics has been developed and putative risk factors resulting in different relative BA are summarized. Only two publications were found that claimed to contain failed bioequivalence studies in a pediatric population. The vast majority of pediatric data comes from relative bioavailability studies of different formulations. Analysis of the developed database has highlighted that particular care is needed for BCS class 2 drugs when assessing $\mathrm{BE}$ in pediatrics. Additional work is warranted to use in vitro and in silico models for evaluating subtle changes in GI physiology that can affect the absorption of drugs in pediatric populations, particularly GI volume, motility, and transit times.

\section{SUPPLEMENTARY INFORMATION}

The online version contains supplementary material available at https://doi.org/10.1208/s12248-021-00592-y.

\section{ACKNOWLEDGEMENTS}

GP and HKB are grateful to U.S. FDA members for valuable contribution in providing useful comments and advice on this manuscript.

\section{FUNDING}

This review work is carried out by the University of Birmingham under the project "Research Proposal to better understand risk mitigation in the evaluation of relative bioavailability of pediatric generic products" funded by U.S. FDA through FDA BAA-17-00123 (Pediatric Generic Contract). Dr. Youssef Mousa was supported by an appointment to the Research Participation Program at CDER, administered by the Oak Ridge Institute for Science and Education (ORISE) through an interagency agreement between the U.S. Department of Energy and the FDA.

\section{DECLARATIONS}

Conflict of Interest The authors declare no competing interests.

Disclaimer The opinions expressed in this article are those of the authors and should not be interpreted as the position of the U.S. FDA and the cases being presented do not imply FDA's endorsement of the products. 
Open Access This article is licensed under a Creative Commons Attribution 4.0 International License, which permits use, sharing, adaptation, distribution and reproduction in any medium or format, as long as you give appropriate credit to the original author(s) and the source, provide a link to the Creative Commons licence, and indicate if changes were made. The images or other third party material in this article are included in the article's Creative Commons licence, unless indicated otherwise in a credit line to the material. If material is not included in the article's Creative Commons licence and your intended use is not permitted by statutory regulation or exceeds the permitted use, you will need to obtain permission directly from the copyright holder. To view a copy of this licence, visit http://creativecommons.org/licenses/by/4.0/.

\section{REFERENCES}

1. USFDA. Section 505(j)(8)(B)(i) FD\&C Act Available from: https://www.fda.gov/regulatory-information/federal-food-drugand-cosmetic-act-fdc-act/fdc-act-chapter-v-drugs-and-devices. Accessed March 2021.

2. USFDA. 505(j)(8)(B)(ii), (C) of the FD\&C Act; 21 CFR Available from: https://www.accessdata.fda.gov/scripts/cdrh/ cfdocs/cfcfr/CFRSearch.cfm?fr=329.100. Accessed March 2021.

3. USFDA. Draft Guidance for Industry: Bioavailability Studies Submitted in NDAs or INDs-General Considerations. 2019 Available from: https://www.fda.gov/regulatory-information/ search-fda-guidance-documents/bioavailability-studies-submitted-ndas-or-inds-general-considerations. Accessed March 2021.

4. Ricci BM. Bridging studies in support of oral pediatric formulation development. Int J Pharm. 2013;457(1):323-6. https://doi.org/10.1016/j.ijpharm.2013.07.074.

5. Makhlouf FT, Grosser SC, Schuirmann DJ. Basic statistical considerations. In: Yu LX, Li BV, editors. FDA bioequivalence standards. New York, NY: Springer New York; 2014. p. 55-93.

6. Batchelor HK, Fotaki N, Klein S. Paediatric oral biopharmaceutics: key considerations and current challenges. Adv Drug Deliv Rev. 2014;73:102-26. https://doi.org/10.1016/ j.addr.2013.10.006

7. Burckart GJ. Clinical pharmacology and biopharmaceutic considerations in pediatric global drug development. Am Pharm Rev. 2009;12(6):28-32.

8. Kasirye P, Kendall L, Adkison KK, Tumusiime C, Ssenyonga M, Bakeera-Kitaka S, et al. Pharmacokinetics of antiretroviral drug varies with formulation in the target population of children with HIV-1. Clin Pharmacol Ther. 2012;91(2):272-80. https://doi.org/10.1038/clpt.2011.225.

9. Crémieux AC, Katlama C, Gillotin C, Demarles D, Yuen GJ, Raffi F. A comparison of the steady-state pharmacokinetics and safety of abacavir, lamivudine, and zidovudine taken as a triple combination tablet and as abacavir plus a lamivudinezidovudine double combination tablet by HIV-1-infected adults. Pharmacotherapy. 2001;21(4):424-30. https://doi.org/ 10.1592/phco.21.5.424.34497.

10. Adkison K, Wolstenholme A, Lou Y, Zhang Z, Eld A, Perger $\mathrm{T}$, et al. Effect of sorbitol on the pharmacokinetic profile of lamivudine oral solution in adults: an open-label, randomized study. Clin Pharmacol Ther. 2018;103(3):402-8. https://doi.org/ 10.1002/cpt.943.

11. Abdel-Rahman SM, Amidon GL, Kaul A, Lukacova V, Vinks AA, Knipp GT. Summary of the national institute of child health and human development-best pharmaceuticals for children act pediatric formulation initiatives workshop-pediatric biopharmaceutics classification system working group. Clin Ther. 2012;34(11):S11-24. https:// doi.org/10.1016/j.clinthera.2012.09.014.

12. Batchelor H, Ernest T, Flanagan T, Klein S, Turner R, Fotaki $\mathrm{N}$, et al. Towards the development of a paediatric biopharmaceutics classification system: results of a survey of experts. Int J Pharm. 2016;511(2):1151-7. https://doi.org/ 10.1016/j.jpharm.2016.06.115.

13. Charoo NA, Cristofoletti R, Dressman JB. Risk assessment for extending the biopharmaceutics classification system-based biowaiver of immediate release dosage forms of fluconazole in adults to the paediatric population. J Pharm Pharmacol. 2015;67(8):1156-69. https://doi.org/10.1111/jphp.12411.

14. Delmoral-sanchez JM, Gonzalez-alvarez I, Gonzalez-alvarez M, Navarro A, Bermejo M. Classification of WHO essential oral medicines for children applying a provisional pediatric biopharmaceutics classification system. Pharmaceutics. 2019;11(11). https://doi.org/10.3390/pharmaceutics11110567.

15. Gandhi SV, Rodriguez W, Khan M, Polli JE. Considerations for a pediatric biopharmaceutics classification system (BCS): application to five drugs. AAPS PharmSciTech. 2014;15(3):601-11. https://doi.org/10.1208/s12249-014-0084-0.

16. Aburub A, Sperry DC, Bhattachar S, Lobo E, Ding X, Rose JP. Relative bioavailability risk assessment: a systematic approach to assessing in vivo risk associated with $\mathrm{CM} \& \mathrm{C}$ related changes. J Pharm Sci. 2019;108(1):8-17. https://doi.org/ 10.1016/j.xphs.2018.07.012.

17. Byakika-Tusiime J, Chinn LW, Oyugi JH, Obua C, Bangsberg DR, Kroetz DL. Steady state bioequivalence of generic and innovator formulations of stavudine, lamivudine, and nevirapine in HIV-infected Ugandan adults. PLoS One. 2008;3(12):e3981. https://doi.org/10.1371/journal.pone.0003981.

18. Bedding A. Design and analysis of bioavailability and bioequivalence studies (Third Edition), Shein-Chung Chow, Jenpei Liu (2008) ISBN: 1584886684; 760 pages; \$99.95, £63.99 Chapman and Hall/CRC; http://www.crcpress.com. Pharmaceutical Statistics. 2012;11(1):86-. 10.1002/pst.475.

19. PubMed. https://www.ncbi.nlm.nih.gov/pubmed/. Accessed Jan 2021.

20. The Cochrane Library. https://www.cochranelibrary.com. Accessed Jan 2021.

21. Google Scholar https://www.google.com/. Accessed Jan 2021.

22. van der Meersch A, Dechartres A, Ravaud P. Quality of reporting of bioequivalence trials comparing generic to brand name drugs: a methodological systematic review. PLoS One. 2011;6(8):e23611. https://doi.org/10.1371/journal.pone.0023611.

23. Kaur P, Jiang X, Stier E. Analysis of non-pivotal bioequivalence studies submitted in abbreviated new drug submissions for delayed-release drug products. J Pharm Pharm Sci. 2017;20:252-7. https://doi.org/10.18433/j39s6z.

24. Curtis JJ, Group $\mathrm{ftC}-\mathrm{S}$. Lack of bioequivalence of two Sandimmune ${ }^{\circledR}$ cyclosporine formulations in renal transplant patients who absorb cyclosporine poorly. Transplantation. 1998;65(12):S65.

25. Meyer MC, Straughn AB, Jarvi EJ, Wood GC, Pelsor FR, Shah VP. The bioinequivalence of carbamazepine tablets with a history of clinical failures. Pharm Res. 1992;9(12):1612-6. https://doi.org/10.1023/A:1015872626887.

26. Carswell JM, Gordon JH, Popovsky E, Hale A, Brown RS. Generic and brand-name L-thyroxine are not bioequivalent for children with severe congenital hypothyroidism. J Clin Endocrinol Metab. 2013;98(2):610-7. https://doi.org/10.1210/ jc.2012-3125.

27. Wishart DS, Feunang YD, Guo AC, Lo EJ, Marcu A, Grant JR, et al. DrugBank 5.0: a major update to the DrugBank database for 2018. Nucleic Acids Res. 2018;46(D1):D1074-d82. https://doi.org/10.1093/nar/gkx1037.

28. Yu LX, Jiang W, Zhang X, Lionberger R, Makhlouf F, Schuirmann DJ, et al. Novel bioequivalence approach for narrow therapeutic index drugs. Clin Pharmacol Ther. 2015;97(3):286-91. https://doi.org/10.1002/cpt.28.

29. U.S.FDA. Product-specific guidances for generic drug development. Available from: https://www.accessdata.fda.gov/ scripts/cder/psg/index.cfm. Accessed March 2021.

30. NICHD-FDA. Intra-agency agreement between the Eunice Kennedy Shriver National Institute of Child Health and Human Development (NICHD) and the U.S. Food and Drug Administration (FDA) Oral Formulations Platform-Report 1. 2014; Available from: https://www.nichd.nih.gov/sites/ 
default/files/inline-files/Formulations_Platform_Report1.pdf. Accessed March 2021.

31. Shawahna R. Pediatric biopharmaceutical classification system: using age-appropriate initial gastric volume. AAPS J. 2016;18(3):728-36. https://doi.org/10.1208/s12248-016-9885-2.

32. Acott PD, Crocker JF, Renton KW. Evaluation of performance factors affecting two formulations of cyclosporine in pediatric renal transplant patients. Transplant Proc. 2006;38(9):2835-41. https://doi.org/10.1016/ j.transproceed.2006.08.096.

33. Crocker J, Renton K, Wade A, McLellan H, Acott P. Acute allograft rejection following conversion to a new cyclosporine formulation in pediatric renal transplant patients. Transplant Proc. 1998;30(5):2002-5. https://doi.org/10.1016/s00411345(98)00512-0.

34. Fukuyama Y, Kitahara H, Goto T. Comparative study of bioavailabilities of different phenytoin preparations. Brain Dev. 1982;4(1):35-43. https://doi.org/10.1016/S03877604(82)80099-5.

35. Jacobo-Cabral CO, García-Roca P, Reyes H, Lozada-Rojas L, Cruz-Antonio L, Medeiros M, et al. Limustin ${ }^{\circledR}$, a noninnovator tacrolimus formulation, yields reduced drug exposure in pediatric renal transplant recipients. Pediatr Transplant. 2014;18(7):706-13. https://doi.org/10.1111/petr.12335.

36. Kabasakul SC, Clarke M, Kane H, Karsten J, Clark G. Comparison of Neoral and Sandimmun cyclosporin A pharmacokinetic profiles in young renal transplant recipients. Pediatr Nephrol. 1997;11(3):318-21. https://doi.org/10.1007/ s004670050284.

37. Medeiros M, Gómez AC, Urizar JP, Campos-Sepúlveda AE, Saldaña IM, Ramírez LE, et al. Bioavailability of two oral formulations of cyclosporin A in uremic children before renal transplantation. Pediatr Transplant. 1998;2(2):145-9.

38. Melter M, Rodeck B, Kardorff R, Hoyer PF, Brodehl J. Pharmacokinetics of cyclosporine in pediatric long-term liver transplant recipients converted from Sandimmun to Neoral. Transpl Int. 1997;10(6):419-25. https://doi.org/10.1007/ s001470050080.

39. Merke DP, Cho D, Anton Calis K, Keil MF, Chrousos GP. Hydrocortisone suspension and hydrocortisone tablets are not bioequivalent in the treatment of children with congenital adrenal hyperplasia. J Clin Endocrinol Metab. 2001;86(1):4415. https://doi.org/10.1210/jcem.86.1.7275.

40. Matsukura M, Ikeda T, Higashi A, Matsuda I. Relative bioavailability of two different phenytoin preparations. Dev Pharmacol Ther. 1984;7:160-8. https://doi.org/10.1159/ 000457159.

41. Mueller BU, Sleasman J, Nelson RP, Smith S, Deutsch PJ, Ju $\mathrm{W}$, et al. A phase I/II study of the protease inhibitor indinavir in children with HIV infection. Pediatrics. 1998;102(1):101-9. https://doi.org/10.1542/peds.102.1.101.

42. Salman S, Griffin S, Kose K, Pitus N, Winmai J, Moore B, et al. Pharmacokinetic properties of conventional and double-dose sulfadoxine-pyrimethamine given as intermittent preventive treatment in infancy. Antimicrob Agents Chemother. 2011;55(4):1693-700. https://doi.org/10.1128/aac.01075-10.

43. ter Heine R, Scherpbier HJ, Crommentuyn KM, Bekker V, Beijnen JH, Kuijpers TW, et al. A pharmacokinetic and pharmacogenetic study of efavirenz in children: dosing guidelines can result in subtherapeutic concentrations. Antivir Ther. 2008;13(6):779-87.

44. Wang LH, Wiznia AA, Rathore MH, Chittick GE, Bakshi SS, Emmanuel PJ, et al. Pharmacokinetics and safety of single oral doses of emtricitabine in human immunodeficiency virusinfected children. Antimicrob Agents Chemother. 2004;48(1):183-91. https://doi.org/10.1128/aac.48.1.183191.2004.

45. Bökenkamp A, Offner G, Hoyer PF, Vester U, Wonigeit K, Brodehl J. Improved absorption of cyclosporin A from a new microemulsion formulation: implications for dosage and monitoring. Pediatr Nephrol. 1995;9(2):196-8. https://doi.org/ 10.1007/bf00860745.

46. Fu LW, Yang LY, Chen WP, Lin CY. Cyclosporin pharmacokinetics following administration of capsules and Neoral in paediatric patients with lupus nephritis. Br J Clin Pharmacol.
1997;44(2):125-7. https://doi.org/10.1046/j.13652125.1997.00634.x.

47. Best B, Capparelli E, Diep H, Rossi S, Farrell M, Williams E, et al. Pharmacokinetics of lopinavir/ritonavir crushed versus whole tablets in children. J Acquir Immune Defic Syndr (1999). 2011;58:385-91. https://doi.org/10.1097/ QAI.0b013e318232b057.

48. Camfield P, Hwang P, Camfield C, Fraser A, Soldin S. alQuadah AK. The pharmacology of chewable versus regular carbamazepine in chronically treated children with epilepsy. Can J Neurol Sci Le journal canadien des sciences neurologiques. 1992;19(2):204-7.

49. Hodges S, Forsythe WI, Gillies D, Remington H, Cawood A. Bio-availability and dissolution of three phenytoin preparations for children. Dev Med Child Neurol. 1986;28(6):708-12. https://doi.org/10.1111/j.1469-8749.1986.tb03921.x.

50. Portman RJ, Meier-Kriesche HU, Swinford R, Brannan P, Kahan BD. Reduced variability of Neoral pharmacokinetic studies in pediatric renal transplantation. Pediatr Nephrol. 2000;15(1):2-6. https://doi.org/10.1007/s004670000435.

51. McIlleron H, Hundt H, Smythe W, Bekker A, Winckler J, van der Laan L, et al. Bioavailability of two licensed paediatric rifampicin suspensions: implications for quality control programmes. Int J Tuberc Lung Dis. 2016;20(7):915-9. https:// doi.org/10.5588/ijtld.15.0833.

52. Reding R, Sokal E, Paul K, Janssen M, Evrard V, Wilmotte L, et al. Efficacy and pharmacokinetics of tacrolimus oral suspension in pediatric liver transplant recipients. Pediatr Transplant. 2002;6(2):124-6. https://doi.org/10.1034/j.13993046.2002.01052.x.

53. van Mourik IDM, Thomson M, Kelly DA. Comparison of pharmacokinetics of neoral and sandimmune in stable pediatric liver transplant recipients. Liver Transplant Surg. 1999;5(2):107-11. https://doi.org/10.1002/lt.500050203.

54. Krmar RT, Wuhl E, Ding R, Aulmann M, Schärer K. Pharmacokinetics of a new microemulsion formulation of cyclosporin A (Neoral) in young patients after renal transplantation. Transpl Int. 1996;9(5):476-80. https://doi.org/ 10.1007/BF00336825.

55. Dunn S, Cooney G, Sommerauer J, Lindsay C, McDiarmid S, Wong RL, et al. Pharmacokinetics of an oral solution of the microemulsion formulation of cyclosporine in maintenance pediatric liver transplant recipients. Transplantation. 1997;63(12):1762-7.

56. Alvarez F, Atkison PR, Grant DR, Guilbault N, Jones AB, Kim PS, et al. NOF-11: a one-year pediatric randomized double-blind comparison of neoral versus sandimmune in orthotopic liver transplantation. Transplantation. 2000;69(1):87-92. https://doi.org/10.1097/00007890-20000115000016.

57. Kelles A, Herman J, Budya Tjandra-Maga T, Van DammeLombaerts R. Sandimmune ${ }^{\circledR}$ to Neoral ${ }^{\circledR}$ conversion and value of abbreviated AUC monitoring in stable pediatric kidney transplant recipients. Pediatr Transplant. 1999;3(4):282-7. https://doi.org/10.1034/j.1399-3046.1999.00058.x.

58. Chokephaibulkit K, Cressey TR, Capparelli E, Sirisanthana V, Muresan P, Hongsiriwon S, et al. Pharmacokinetics and safety of a new paediatric fixed-dose combination of zidovudine/ lamivudine/nevirapine in HIV-infected children. Antivir Ther. 2011;16(8):1287-95. https://doi.org/10.3851/IMP1931.

59. Vondrak K, Dhawan A, Parisi F, Grenda R, Debray D, Marks $\mathrm{SD}$, et al. Comparative pharmacokinetics of tacrolimus in de novo pediatric transplant recipients randomized to receive immediate- or prolonged-release tacrolimus. Pediatr Transplant. 2018;22(8):e13289. https://doi.org/10.1111/petr.13289.

60. Ellis JC, L'Homme RF, Ewings FM, Mulenga V, Bell F, Chileshe R, et al. Nevirapine concentrations in HIV-infected children treated with divided fixed-dose combination antiretroviral tablets in Malawi and Zambia. Antivir Ther. 2007;12(2):253-60.

61. Eeg-Olofsson O, Nilsson HL, Tonnby B, Arvidsson J, Grahn PA, Gylje H, et al. Diurnal variation of carbamazepine and carbamazepine-10,11-epoxide in plasma and saliva in children with epilepsy: a comparison between conventional and slow- 
release formulations. J Child Neurol. 1990;5(2):159-65. https:// doi.org/10.1177/088307389000500219.

62. Vanprapar N, Cressey TR, Chokephaibulkit K, Muresan P, Plipat N, Sirisanthana V, et al. A chewable pediatric fixed-dose combination tablet of stavudine, lamivudine, and nevirapine: pharmacokinetics and safety compared with the individual liquid formulations in human immunodeficiency virus-infected children in Thailand. Pediatr Infect Dis J. 2010;29(10):940-4. https://doi.org/10.1097/INF.0b013e3181e2189d.

63. Tolbert JA, Bai S, Abdel-Rahman SM, August KJ, Weir SJ, Kearns GL, et al. Pharmacokinetics of two 6-mercaptopurine liquid formulations in children with acute lymphoblastic leukemia. Pediatr Blood Cancer. 2017;64(8):e26465. https:// doi.org/10.1002/pbc.26465.

64. Mukherjee A, Singla M, Velpandian T, Sirohiwal A, Vajpayee M, Singh R, et al. Pharmacokinetics of nevirapine, stavudine and lamivudine in Indian HIV-infected children receiving generic fixed dose combinations. Indian Pediatr. 2014;51(3):191-7. https://doi.org/10.1007/s13312-014-0382-3.

65. Salem AH, Fletcher CV, Brundage RC. Pharmacometric characterization of efavirenz developmental pharmacokinetics and pharmacogenetics in human immunodeficiency virus infected children. Antimicrob Agents Chemother. 2013:AAC.01738-13. https://doi.org/10.1128/aac.01738-13.

66. Musiime V, Fillekes Q, Kekitiinwa A, Kendall L, Keishanyu R, Namuddu R, et al. The pharmacokinetics and acceptability of lopinavir/ritonavir minitab sprinkles, tablets, and syrups in african HIV-infected children. J Acquir Immune Defic Syndr. 2014;66(2):148-54. https://doi.org/10.1097/ qai.0000000000000135.

67. Cassio A, Monti S, Rizzello A, Bettocchi I, Baronio F, D'Addabbo $G$, et al. Comparison between liquid and tablet formulations of levothyroxine in the initial treatment of congenital hypothyroidism. J Pediatr. 2013;162(6):1264-9, 9.e1-2. https://doi.org/10.1016/j.jpeds.2012.11.070.

68. Pollock L, Else L, Poerksen G, Molyneux E, Moons P, Walker $S$, et al. Pharmacokinetics of nevirapine in HIV-infected children with and without malnutrition receiving divided adult fixed-dose combination tablets. J Antimicrob Chemother. 2009;64(6):1251-9. https://doi.org/10.1093/jac/dkp358.

69. Allegaert K, van den Anker J. Neonatal drug therapy: the first frontier of therapeutics for children. Clin Pharmacol Ther. 2015;98(3):288-97. https://doi.org/10.1002/cpt.166.

70. Bowles A, Keane J, Ernest T, Clapham D, Tuleu C. Specific aspects of gastro-intestinal transit in children for drug delivery design. Int J Pharm. 2010;395(1-2):37-43. https://doi.org/ 10.1016/j.ijpharm.2010.04.048.

71. Alcorn J, McNamara PJ. Pharmacokinetics in the newborn. Adv Drug Deliv Rev. 2003;55(5):667-86. https://doi.org/ 10.1016/s0169-409x(03)00030-9.

72. Davis SS, Hardy JG, Fara JW. Transit of pharmaceutical dosage forms through the small intestine. Gut. 1986;27(8):88692. https://doi.org/10.1136/gut.27.8.886.

73. Gómez Acotto C, Antonelli C, Flynn D, McDaid D, Roldán EJ. Upper gastrointestinal tract transit times of tablet and drinkable solution formulations of alendronate: a bioequivalence and a quantitative, randomized study using video deglutition. Calcif Tissue Int. 2012;91(5):325-34. https:// doi.org/10.1007/s00223-012-9639-9.

74. Thyssen A, Solanki B, Gonzalez M, Leitz G, Treem W, Mannaert E. Pharmacokinetics of rabeprazole granules versus tablets, and the effect of food on the pharmacokinetics of rabeprazole granules in healthy adults-cross-study comparison. Clin Pharmacol Drug Dev. 2014;3(5):406-16. https:// doi.org/10.1002/cpdd.118.

75. Tirpude RN, Puranik PK. Rabeprazole sodium delayed-release multiparticulates: effect of enteric coating layers on product performance. J Adv Pharm Technol Res. 2011;2(3):184-91. https://doi.org/10.4103/2231-4040.85539. Accessed Dec 2020.

76. Organization WH. Proposal to waive in vivo bioequivalence requirements for WHO model list of essential medicines immediate-release, solid oral dosage forms. WHO Technical Report Series, No. 937, 2006, Annex 8. 2006. Accessed March 2021
77. Shugarts S, Benet LZ. The role of transporters in the pharmacokinetics of orally administered drugs. Pharm Res. 2009;26(9):2039-54. https://doi.org/10.1007/s11095-009-9924-0.

78. Wu CY, Benet LZ. Predicting drug disposition via application of BCS: transport/absorption/ elimination interplay and development of a biopharmaceutics drug disposition classification system. Pharm Res. 2005;22(1):11-23. https://doi.org/10.1007/ s11095-004-9004-4.

79. Batchelor HK, Marriott JF. Paediatric pharmacokinetics: key considerations. Br J Clin Pharmacol. 2015;79(3):395-404. https://doi.org/10.1111/bcp.12267.

80. Ehrnebo M, Agurell S, Jalling B, Boréus LO. Age differences in drug binding by plasma proteins: studies on human foetuses, neonates and adults. Eur J Clin Pharmacol. 1971;3(4):189-93. https://doi.org/10.1007/bf00565004.

81. Weiss CF, Glazko AJ, Weston JK. Chloramphenicol in the newborn infant. A physiologic explanation of its toxicity when given in excessive doses. N Engl J Med. 1960;262:787-94. https://doi.org/10.1056/nejm196004212621601.

82. Fellay J, Marzolini C, Meaden ER, Back DJ, Buclin T, Chave $\mathrm{JP}$, et al. Response to antiretroviral treatment in HIV-1infected individuals with allelic variants of the multidrug resistance transporter 1: a pharmacogenetics study. Lancet. 2002;359(9300):30-6. https://doi.org/10.1016/s01406736(02)07276-8.

83. Burkhardt RT, Leppik IE, Blesi K, Scott S, Gapany SR, Cloyd JC. Lower phenytoin serum levels in persons switched from brand to generic phenytoin. Neurology. 2004;63(8):1494-6. https://doi.org/10.1212/01.Wnl.0000142091.47698.A2.

84. Soryal I, Richens A. Bioavailability and dissolution of proprietary and generic formulations of phenytoin. J Neurol Neurosurg Psychiatry. 1992;55(8):688-91. https://doi.org/ 10.1136/jnnp.55.8.688. Accessed Dec 2020

85. Suthisisang C, Payakachat N, Chulavatnatol S, Towanabut S. Bioavailability of phenytoin sodium capsules available in Thailand. Part II: in vivo study. J Med Assoc Thail. 1998;81(1):64-70.

86. Rosenbaum DH, Rowan AJ, Tuchman L, French JA. Comparative bioavailability of a generic phenytoin and Dilantin. Epilepsia. 1994;35(3):656-60. https://doi.org/10.1111/j.15281157.1994.tb02487.x.

87. Tsai JJ, Lai ML, Yang YH, Huang JD. Comparison on bioequivalence of four phenytoin preparations in patients with multiple-dose treatment. J Clin Pharmacol. 1992;32(3):272-6. https://doi.org/10.1002/j.1552-4604.1992.tb03836.x.

88. NHS UK. Phenytoin Available from: https://www.nhs.uk/medicines/phenytoin/.

89. U.S.FDA. Product specific guidance for phenytoin oral suspension 2017; Available from: https:// www.accessdata.fda.gov/drugsatfda_docs/psg/ Phenytoin_oral\%20suspension_RLD\%20008762_RV0317.pdf.

90. Patel RB, Rogge MC, Selen A, Goehl TJ, Shah VP, Prasad $\mathrm{VK}$, et al. Bioavailability of hydrocortisone from commercial 20-mg tablets. J Pharm Sci. 1984;73(7):964-6. https://doi.org/ 10.1002/jps.2600730726.

91. Henwood SQ, Liebenberg W, Tiedt LR, Lötter AP, de Villiers MM. Characterization of the solubility and dissolution properties of several new rifampicin polymorphs, solvates, and hydrates. Drug Dev Ind Pharm. 2001;27(10):1017-30. https:// doi.org/10.1081/DDC-100108364.

92. Uematsu FTS, Fukuyama Y, Yakou S. A clinicopharmacological study of a phenytoin granule preparation in epileptic children. Brain Dev. 1982;14(3):324-32.

93. Papadatou-Soulou E, Mason J, Parsons C, Oates A, Thyagarajan M, Batchelor HK. Magnetic resonance imaging quantification of gastrointestinal liquid volumes and distribution in the gastrointestinal tract of children. Mol Pharm. 2019;16(9):3896-903. https://doi.org/10.1021/ acs.molpharmaceut.9b00510.

94. U.S.FDA. General clinical pharmacology considerations for pediatric studies for drugs and biological products guidance for industry. 2014; Available from: https://www.fda.gov/media/ 90358/download. 
95. Kotler DP, Gaetz HP, Lange M, Klein EB, Holt PR. Enteropathy associated with the acquired immunodeficiency syndrome. Ann Intern Med. 1984;101(4):421-8. https://doi.org/ 10.7326/0003-4819-101-4-421.

96. Crakes KR, Jiang G. Gut microbiome alterations during HIV/ SIV infection: implications for HIV cure. Front Microbiol. 2019;10:1104. https://doi.org/10.3389/fmicb.2019.01104.

97. Brenchley JM, Douek DC. HIV infection and the gastrointestinal immune system. Mucosal Immunol. 2008;1(1):23-30. https://doi.org/10.1038/mi.2007.1.

98. Poles MA, Fuerst M, McGowan I, Elliott J, Rezaei A, Mark D, et al. HIV-related diarrhea is multifactorial and fat malabsorption is commonly present, independent of HAART. Am J Gastroenterol. 2001;96(6):1831-7. https://doi.org/10.1111/ j.1572-0241.2001.03879.x

99. Oude Munnink BB, Canuti M, Deijs M, de Vries M, Jebbink MF, Rebers S, et al. Unexplained diarrhoea in HIV-1 infected individuals. BMC Infect Dis. 2014;14(1):22. https://doi.org/ 10.1186/1471-2334-14-22.

100. Guarino A, Bruzzese E, De Marco G, Buccigrossi V. Management of gastrointestinal disorders in children with HIV infection. Pediatr Drugs. 2004;6(6):347-62. https://doi.org/ 10.2165/00148581-200406060-00003.

101. Whitington PF, Emond JC, Whitington SH, Broelsch CE, Baker AL. Small-bowel length and the dose of cyclosporine in children after liver transplantation. $\mathrm{N}$ Engl J Med. 1990;322(11):733-8. https://doi.org/10.1056/ nejm199003153221105.

102. Van Peer A. Variability and impact on design of bioequivalence studies. Basic Clin Pharmacol Toxicol. 2010;106(3):14653. https://doi.org/10.1111/j.1742-7843.2009.00485.x.

103. Naicker D, Reed PW, Ronaldson J, Kara T, Wong W, Prestidge C. Nationwide conversion to generic tacrolimus in pediatric kidney transplant recipients. Pediatr Nephrol. 2017;32(11):2125-31. https://doi.org/10.1007/s00467-017-3707-3.

104. van Stralen JP. The clinical impact of switching attention deficit hyperactivity disorder patients from OROS(®)-MPH to NovoMPH ER-C(®): a paediatric practice review. Paediatr Child Health. 2013;18(2):70-3. https://doi.org/10.1093/pch/18.2.70.

105. Lomenick JP, Wang L, Ampah SB, Saville BR, Greenwald FI. Generic levothyroxine compared with synthroid in young children with congenital hypothyroidism. J Clin Endocrinol Metab. 2013;98(2):653-8. https://doi.org/10.1210/jc.2012-3558.

106. PENTA. Once vs. twice-daily lopinavir/ritonavir in HIV-1infected children. AIDS. 2015;29(18):2447-57. https://doi.org/ 10.1097/qad.0000000000000862.

107. Jacquemin E, Hermeziu B, Kibleur Y, Friteau I, Mathieu D, Le $\mathrm{Coz} F$, et al. Bioavailability of oral vitamin $\mathrm{E}$ formulations in adult volunteers and children with chronic cholestasis or cystic fibrosis. J Clin Pharm Ther. 2009;34(5):515-22. https://doi.org/ 10.1111/j.1365-2710.2009.01027.x.

108. Williams HD, Trevaskis NL, Charman SA, Shanker RM, Charman WN, Pouton CW, et al. Strategies to address low drug solubility in discovery and development. Pharmacol Rev. 2013;65(1):315-499. https://doi.org/10.1124/pr.112.005660.

109. Cristofoletti R, Chiann C, Dressman JB, Storpirtis S. A comparative analysis of biopharmaceutics classification system and biopharmaceutics drug disposition classification system: a cross-sectional survey with 500 bioequivalence studies. J Pharm Sci. 2013;102(9):3136-44. https://doi.org/10.1002/ jps.23515.

110. Ramirez E, Laosa O, Guerra P, Duque B, Mosquera B, Borobia AM, et al. Acceptability and characteristics of 124 human bioequivalence studies with active substances classified according to the Biopharmaceutic Classification System. Br J Clin Pharmacol. 2010;70(5):694-702. https://doi.org/10.1111/ j.1365-2125.2010.03757.x.

111. Hennessey JV, Burman KD, Wartofsky L. The equivalency of two L-thyroxine preparations. Ann Intern Med. 1985;102(6):770-3. https://doi.org/10.7326/0003-4819-102-6-770.

112. Jiang W, Makhlouf F, Schuirmann DJ, Zhang X, Zheng N, Conner D, et al. A bioequivalence approach for generic narrow therapeutic index drugs: evaluation of the referencescaled approach and variability comparison criterion. AAPS J. 2015;17(4):891-901. https://doi.org/10.1208/s12248-015-9753-5. Accessed Dec 2020

113. U.S.FDA. Waiver of in vivo bioavailability and bioequivalence studies for immediate-release solid oral dosage forms based on a biopharmaceutics classification system. Guidance for Industry. December 2017; Available from: https://www.fda.gov/regulatory-information/search-fda-guidance-documents/waivervivo-bioavailability-and-bioequivalence-studies-immediate-release-solid-oral-dosage-forms.

114. Uppoor RS, Vaidyanathan J, Mehta M, Yu LX. Biowaiver and biopharmaceutics classification system. In: Yu LX, Li BV, editors. FDA bioequivalence standards. New York, NY: Springer New York; 2014. p. 119-37.

115. Blakesley V, Awni W, Locke C, Ludden T, Granneman GR, Braverman LE. Are bioequivalence studies of levothyroxine sodium formulations in euthyroid volunteers reliable? Thyroid. $2004 ; 14(3): 191-200$. https://doi.org/10.1089/ 105072504773297867.

116. Hamad ML, Engen W, Morris KR. Impact of hydration state and molecular oxygen on the chemical stability of levothyroxine sodium. Pharm Dev Technol. 2015;20(3):314-9. https://doi.org/10.3109/10837450.2013.862635.

117. Lapeyraque AL, Kassir N, Theoret Y, Krajinovic M, Clermont MJ, Litalien C, et al. Conversion from twice- to once-daily tacrolimus in pediatric kidney recipients: a pharmacokinetic and bioequivalence study. Pediatr Nephrol. 2014;29(6):1081-8. https://doi.org/10.1007/s00467-013-2724-0.

118. Galgatte UC, Jamdade VR, Aute PP, Chaudhari PD. Study on requirements of bioequivalence for registration of pharmaceutical products in USA, Europe and Canada. Saudi Pharm J. 2014;22(5):391-402. https://doi.org/10.1016/j.jsps.2013.05.001.

119. García-Arieta A. The failure to show bioequivalence is not evidence against generics. Br J Clin Pharmacol. 2010;70(3):452-3. https://doi.org/10.1111/j.13652125.2010.03684.x.

Publisher's Note Springer Nature remains neutral with regard to jurisdictional claims in published maps and institutional affiliations. 